DOI: https://doi.org/10.24297/ibt.v8i0.8221

\title{
Extraction and Purification of Antimicrobial Proteins from Datura Stramonium Seed
}

\author{
Surayya Mustapha Muhammad ${ }^{1, *}$, Ibrahim A. Sabo ${ }^{2}$, Ahmed Mohammed Gumel ${ }^{3}$ Fatima I, Alkali ${ }^{4}$ \\ 1,3Faculty of Science, Federal University Dutse, Jigawa Nigeria \\ ${ }^{2}$ Faculty of Pure and Applied Sciences, Federal University Wukari Taraba Nigeria \\ ${ }^{4}$ Faculty of Biomedical Sciences, Bayero University Kano Nigeria \\ Surayya.m@fud.edu.ng
}

\begin{abstract}
Resistant to antibiotics by microbes have become a major global challenge incurring economic and public health burden. Hence, research to develop new effective anti-biotics should be a major consideration to pharmaceutical industries, scientific researchers, Amanda 'scientific researchers and world health organizations at large. This study is conducted to investigate the antimicrobial property of proteins present in the seeds of Datura stramonium. The extraction was carried out using Tris- $\mathrm{HCL}$ buffer prepared from $50 \mathrm{M}$ Tris and $0.3 \mathrm{M} \mathrm{NaCL}$, the proteins were isolated using ammonium sulphate precipitation to obtain $80 \%$ fraction. The isolated and extracted proteins sample were subjected to dialysis in which all the salt was removed and then purified using Ion-exchange chromatography. Acidic and basic fractions of the proteins obtained were subjected to SDS-PAGE electrophoresis to visualize their different molecular weight. More protein band was observed in the basic fraction between $9-45 \mathrm{kDa}$. Antibacterial activities of both acidic and basic proteins were carried out using the paper disc diffusion method against clinical bacterial isolates of $\mathrm{E}$. coli and Klebsiella pneumoniae. More activity was observed in basic protein with a diameter $8 \mathrm{~mm}$ compared to the acidic fraction of $7 \mathrm{~mm}$ in diameter.
\end{abstract}

Keywords: Antibiotic, Protein, Bacteria, SDS-PAGE, Extraction, Phytochemicals.

\section{Introduction}

The dramatic increase of antibiotic resistance, including the emergence of untreatable infections by multiresistant microorganisms there is no doubt that we need novel antimicrobials[1].

The role of plants in the treatment of human traumas and disease have been a great achievement worldwide. There is increase demand of medicinal plant in both developed and developing countries due to the increase recognition of natural products. Medicinal plants are important in both traditional and modern system of medicines[2]. Datura stramonium is a common annual plant from the Solanaceae family. The whole plant of Datura plants contain dangerous levels of phytochemicals such as tropane alkaloids atropine, hyoscyamine and scopolamine which are classified as deliriants, or anticholinergics but the highest amount alkaloids is contained in the ripe seeds[2]. For uninformed users there is high risk of fatal overdose, many recreational users who ingest the plant have been hospitalized due to its psychoactive effects[2]. Acute Jimsonweed poisoning symptoms include dryness of the mouth and extreme thirst, dryness of the skin, pupil dilate ion, impaired vision, urinary retention, rapid heartbeat, confusion, restlessness, hallucinations, and loss of consciousness [2]. Accidental poisoning have been reported when D. stramonium plant was eaten accidentally[2]. Overdosing on Jimson weed will lead to: Visual hallucinations, Disorientation, Speech incomprehension, Dilated pupils, Can be fatal, Many cases of severe acute anticholinergic toxidrome, Delirium, agitation and seizures, Scopolamine is known to be the main cause of hallucinations[3]. Bioactive constituents, ethno pharmacology along with the scientifically claimed medicinal uses of $D$. stramonium have been reported by several reviewers. Different parts of $D$. 
stramonium have also been reported to contain several alkaloids, carbohydrates, fat, proteins and tannins. The presence of active chemical constituents makes the plant to have various types of activities such as analgesic antiasthma tic effect. In vitro and in vivo pharmacological studies have been conducted, as such investigation and quantification of Phyto-constituents and pharmacological profile needs to be conducted[3].

Antimicrobial activity of the plant defensins are active against a broad spectrum of plant pathogens such as bacteria, yeast, oomycetes, and necrotrophic pathogens[4]. Important activities in medical applications such as anticancer activity and antiviral activity have also been observed [5]. The membrane glucosylceramides of susceptible yeast and fungi interact with plant defensins which induce membrane permeabilization and fungal cell death [6]. The natural antimicrobial peptides are mostly 10 to 50 amino acids in length, range in size from 2 to $9 \mathrm{kDa}$, are positively charged and contain a high position of hydrophobic amino acid, and often display a helical structure

For long, the use of antimicrobial peptides (AMPs) as novel antibiotics has been proposed and widely accepted. AMPs have been proposed for the treatment of microbial infections, specifically those caused by antibioticresistant bacteria, due to their rapid and broad spectrum of antimicrobial properties along with their generalized mode of action [1].

The present study aimed to isolate, purify, characterize and observed the activity of antimicrobial protein against some bacterial isolates which can further be used to improve the production of more anti-biotics.

\section{Materials and Methods}

\section{Sample Collection}

Fresh sample of Datura stramonium seeds were collected from the local area of greater Noida, India which was then transported to the laboratory for further analysis.

\section{Sample Preparation}

The sample was prepared using the method of [3]. Fresh seeds of Datura stramonium were soaked in $200 \mathrm{ml}$ extraction (tris) buffer and crushed using motor and pestle magnetic stirrer was used to mix the solution for proper homogenization for $6 \mathrm{hrs}$. The homogenate was filtered through double layered muslin cloth and centrifuged at $5000 \mathrm{rpm}$ for $15 \mathrm{~min}$ at $4{ }^{\circ} \mathrm{C}$. After the centrifugation two fractions of the sample was obtained supernatant and pellet. Pellet was discarded and the supernatant was used for further analysis.

\section{Extraction of Total Soluble Proteins}

The method used for the protein isolation was carried out using the monogram table, total soluble protein was first precipitated using $80 \%$ and $20 \%$ ammonium sulphate and centrifuged at $6000 \mathrm{rpm}$ for $15 \mathrm{~min}$ at $4{ }^{\circ} \mathrm{C}$ which is a method used to isolate proteins by altering their solubility as described by [7]. More protein was obtained from $80 \%$ precipitation which was then fractionated by cation exchange chromatography, which significantly enrich the activity of some eluted fraction. Dialysis was further carried out for three (3) days with 10kda dialysis membrane to reduce salt and other small molecular weight contaminant excluding proteins.

\section{Purification}

Cation-exchange chromatography was used which is based on the electric charge of the protein molecule.CM sephadex cation exchange gel column was used. The gel was pre equilibrated with $50 \mathrm{mM}$ Tris-buffer of $8.0 \mathrm{pH}$ after which the proteins sample was loaded onto the column, the negatively charged proteins molecule (acidic protein) have no affinity for the stationary phase therefore come out of the column and collected as an eluent, after all the acidic proteins were collected, the column was washed with $500 \mathrm{ml}$ of $50 \mathrm{mM}$ Tris-buffer of $8.0 \mathrm{pH}$ to 
elute all the unbounded proteins. The basic (positively charged) protein bind to chloride ion therefore get eluted out, $50 \mathrm{mM}$ Tris $-\mathrm{HCl}, 0.5 \mathrm{M} \mathrm{NaCl}$ of $\mathrm{pH} 8.0$, which significantly enrich the activity of the fraction.

\section{SDS-PAGE}

SDS- Polyacrylamide gel electrophoresis is the commonly used technique for the characterization of protein.10\% of resolving gel (1.5MTris $\mathrm{pH}(8.8)$ 2.0ul, acrylamide 2.0ul, APS 5.0ul, TEMED10ul water 4ml) was loaded onto the casting tray, the gel was then allowed to polymerized for $20 \mathrm{~min} .10 \%$ of the stacking gel $(0.5 \mathrm{Mtris} \mathrm{pH}(6.8) 0.75 \mathrm{ul}$, APS 2ul, TEMED 7ul, Acrylamide0.38ul, water $1.87 \mathrm{ml}$ ) was also prepared and loaded on top of the resolving gel, comb was placed in the Stacking gel gently, in order to make the wells for loading the samples. The gel Polymerize for $15-20 \mathrm{~min}$ after which the Comb was gently removed without damaging the wells and the plates were then inserted into the electrophoretic chamber followed by the addition of running buffer in both upper and lower chambers.10ul sample for both basic (well 1,2\&3) and acidic (well 4,5\&6) proteins were loaded separately. The gel was then run at $150 \mathrm{Amp}$ for $90 \mathrm{~min}$ after which it was stained using Coomassie brilliant blue [7][8].

The relative molecular weights of the protein with respect to their bands was observed in Kilo Daltons as they appeared as discrete band in the gel as shown in SDS-PAGE profile (Figure 1)

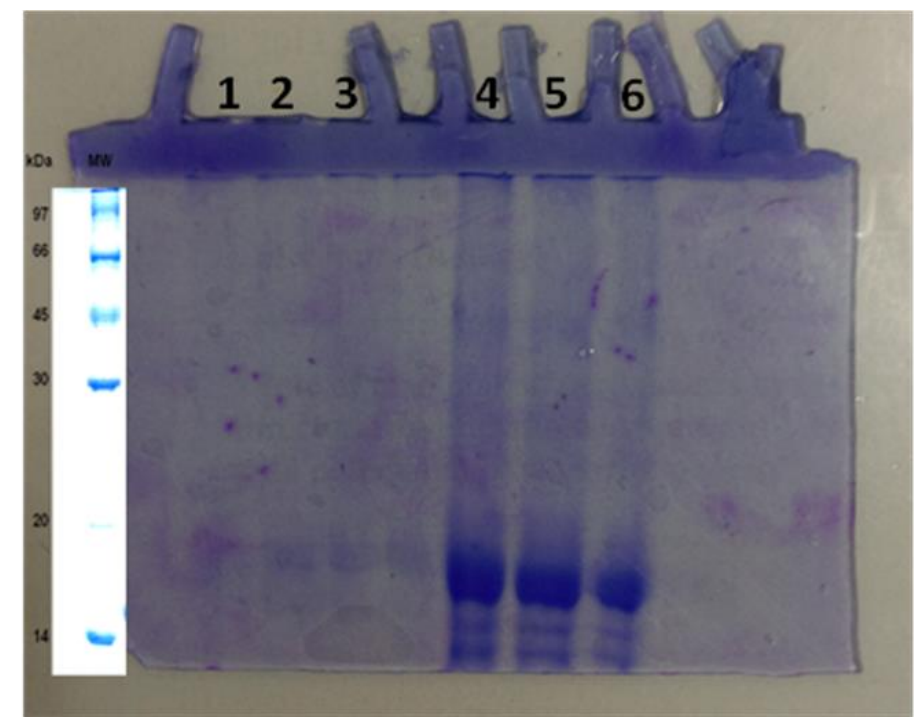

Figure1: Showing SDS-PAGE profile of proteins present in bound and unbound fractions.

\section{Anti-microbial activity on MacConkey Agar plates}

Datura seeds have various phytochemicals and proteins, which make them potent herbal antimicrobial agents against pathogenic bacteria like gram negative (E. coli and Klebsiella pneumoniae). Present study depicted that basic extracts from these seeds can be prepared and purified and used as herbal medicines.

Paper-disc-plate technique was adopted which is the most commonly used technique for determining the susceptibility of micro-organisms to various antibiotics or therapeutic agents. Paper discs containing the protein (basic and acidic) samples were placed on the surface of inoculated plates of E. coli and Klebsiella pneumoniae respectively. The plates were incubated and observed for zones of inhibition around the discs after 24 hours. 


\begin{tabular}{|l|c|c|}
\hline Microorganisms & Acidic fraction & Basic fraction \\
\hline E. coli & X & $\checkmark$ \\
\hline Klebsiella pneumoniae & X & $\checkmark$ \\
\hline
\end{tabular}

Table 4.2: Shows inhibition in different purified fractions

Key: $\mathbf{x}=$ No zone of Inhibition

$\checkmark=$ Presence of zone of Inhibition

\section{Result and Discussion}

Resistance to currently used antibiotics by microorganisms posed threat towards prevention of infectious disease and thus stimulating researchers to discover new antimicrobial agents.

In the present study, total soluble proteins were isolated from Datura stramonium seeds using ammonium sulphate precipitation and dialyzed over night with $10 \mathrm{kda}$ dialysis membrane to reduce salt and other small molecular weight contaminant excluding proteins. Relative molecular weight and the activity of the acidic and basic protein was observed. Many band was observed in basic fraction after staining with Coomassie blue ranging from $9-45 \mathrm{kDa}$ among which is lectin with a molecular weight of $9 \mathrm{kda}$ as reported by [3]. This is also similar to the findings of [7] that purified PME (pectin methlyesterase) from Datura stramonium specie which he found to be $\sim 33 \mathrm{kDa}$. Little or no activity was observed in the acidic fraction when compared with the basic fraction against Escherichia coli and Klebseilla pneumoniae this corroborate with the findings of [2]. Which says that the extract of $D$ stramonium are only active against gram positive bacteria. Basic proteins shows high antimicrobial activity which is also similar to the findings of [3] and [9] that shows activity of lectin against strains of some bacterial isolates (S. aureus, Bacillus cereus, Enterococcus faecalis) this antimicrobial function could be related to the proteins ability to bind to GlcNAc (N-acetyl glucosamine) oligomers which is responsible for the bacterial recognition, where GlcNAc is part of peptidoglycan and murein consisting of the cell wall components. Owing to the bacteriostatic effect, basic protein isolated here could be considered for use as an alternative microbial agent.

Different parts of Datura stramonium specie was reported to have several alkaloids, carbohydrates, fat, protein and tannins, as such the plant shows various types of activities such as analgesic and antiasthma tic activity which may be due to presence of investigated active chemical constituents [2].

\section{Conclusion}

From this result the basic protein extracted from Datura stramonium seeds shows a positive effect against bacterial isolates of E. coli and klebsiella pneumoniae, as such it can be considered to be use as a new source of producing new antibiotics from pharmaceutical industries. Therefore, proper conservation and local awareness of such plant resources should be encouraging, together with the traditional knowledge and scientific findings to the local communities.

\section{Acknowledgements}

None

\section{Conflicts of Interest}

The authors declare there are no conflicts of interest 


\section{Reference}

[1] R. E. W. Hancock and A. Patrzykat, "Clinical Development of Cationic Antimicrobial Peptides: From Natural to Novel Antibiotics," no. 604, pp. 79-83, 2002.

[2] P. Soni, A. A. Siddiqui, J. Dwivedi, and V. Soni, "Pharmacological properties of Datura stramonium L . as a potential medicinal tree: An overview," vol. 2, no. 12, pp. 1002-1008, 2012.

[3] R. Singh and C. Suresh, "Purification and Characterization of a Small Chito-specific Lectin from Datura innoxia Seeds Possessing Anti-microbial Properties," Int. J. Biochem. Res. Rev., vol. 9, no. 2, pp. 1-17, 2016.

[4] A. S. I. Y. P, M. M. P, A. M. P, and F. Garc, "Novel defensin subfamily from spinach ( Spinacia oleracea )," vol. 435, pp. 159-162, 1998.

[5] E. P. Rodrigues, A. R. Torres, J. S. da Silva Batista, L. Huergo, and M. Hungria, "A simple, economical and reproducible protein extraction protocol for proteomics studies of soybean roots," Genet. Mol. Biol., vol. 35, no. SUPPL.1, pp. 348-352, 2012.

[6] K. Thevissen, A. Ghazi, G. W. De Samblanx, C. Brownlee, R. W. Osborn, and W. F. Broekaert, "Fungal Membrane Responses Induced by Plant Defensins and Thionins *," vol. 271, no. 25, pp. 15018-15025, 1996.

[7] S. Dixit, S. K. Upadhyay, H. Singh, and B. Pandey, "Pectin Methylesterase of Datura species, purification , and characterization from Datura stramonium and its application," no. February 2017, 2013.

[8] C. Gurramkonda et al., "recombinant protein production with Pichia pastoris: Application to intracellular production of Hepatitis B surface antigen," vol. 8, pp. 1-8, 2009.

[9] D. Water and D. Water, "Data Data Social Social," pp. 199-231, 2013. 